So detailed and factual a review should be invaluable to many besides crystallographers, and the Editors have given an almost ideal coverage of the field. It includes a statement of fragmentary $\mathrm{X}$-ray and electron diffraction data from a wide variety of substances as well as descriptions of the complete or partial structures which crystal analysis is providing in undiminished numbers.

The only uncertainty that the study of this volume raises in the mind of the reviewer is a doubt as to whether or not we can afford so ideal a review. This doubt applies mainly to the detailed recording of the X-ray data, referred to above, that may help the physical chemist or the person using diffraction for analysis but that contribute little to an exact description of structure. There is value in collecting such items, often widely scattered through the literature; but their description often requires more space than is needed by a first-rate and significant structure. If the uses of X-rays expand still further the coverage of these fragments may ultimately eclipse in bulk what many will consider the primary field of the Reports. In that case it may become more difficult indefinitely to subsidize annual volumes which this coverage has already made rather large and expensive.

\section{Science Office}

American Embassy

London W. 1, England

Structure of Metals. By C. S. Barretr. Pp. xvi+ 661 with many figs. and tables. New York; Toronto; London: McGraw-Hill. 2nd ed., 1952. Price \$10.00; $72 s .6 d$.

'Barrett', as it is known in metallurgical laboratories, was borm a standard work, an aristocrat among text books. Prof. Barrett has now produced a new edition which, while it retains the continuity of style essential for a textbook, also remains a book of reference so up-to-date that it almost discourages the keeping of a card index. There are a number of references dating from the year of publication.

The book has been increased in length by some 100 pages. The chief changes have come in the chapters on the structure of metals and alloys, transformations, annealing texture and all that section of the book devoted to the plastic behaviour of metals. The theoretical part of this section has been entirely remodelled into a new chapter on dislocation theory, which replaces the former chapter on theories of slip. Extensive additions have also been made on theories of annealing textures, the crystallography of martensitic transformations, and neutron diffraction. The changes have not, however, been restricted to addition of new material and the occasional removal of outdated theories. The systematic treatment of basic crystallography has been clarified or amplified in places, the most important amplification being a concise vectorial treatment of the reciprocal lattice and the diffraction laws. Practical techniques have been brought up-to-date, comprising expanded treatments of such topics as chemical analysis by diffraction (including a critical discussion of the ASTM card-index); Geiger, proportional and scintillation counters and their uses, as for texture mapping and the determination of short-range order; $\mathrm{X}$-ray microscopy; Fourier analysis of line profile; and the uses of low-angle scattering (though here the researcher requiring a full discussion will still need to turn to Guinier's book). Only structure analysis continues to be severely rationed for space. Prof. Barrett has evidently decided to give this subject a marginal place in his scheme, and moreover recent advances do not lend themselves to concise treatment, so that one cannot in fairness complain of this. The outstanding references are given.

In spite of the systematic way in which the basic concepts of crystallography are introduced and developed, the book is probably too daunting in scope to serve as a general undergraduate textbook. As the author himself implied in the preface to his first edition, it is better suited to the needs of postgraduate students and researchers, and of final-year undergraduates in physical metallurgy. The graduate starting research in almost any field of physical metallurgy can accompany the author on a tour of inspection which will make him familiar with the state of knowledge, and indeed the flavour of that field. $\mathrm{He}$ will also find, in sufficient detail, those humdrum but essential practical points which will save him much floundering when he rolls up his sleeves in the laboratory.

Department of Metallurgy

R. W. CAHN

The University

Birmingham 15, England 